\title{
Clinico-Pathological Profile of Malignant Abdominal Tumors in Children: Experience of the Pediatric Oncology Unit in Bamako
}

\author{
Abdoul Karim Doumbia1 ${ }^{*}$, Adama Dembele1, Pierre Togo'1, Oumar Coulibaly ${ }^{1}$, \\ Arsene Dackono1, Mohamed Elmouloud Cissé1, Fousseyni Traoré1, Hawa Diall1, \\ Boubacar Togo', Abdoul Aziz Diakité1, Yakaria Coulibaly², Cheick Bougadary Traore ${ }^{3}$, \\ Lala N'drainy Sidibe', Belco Maiga', Diakite Fatoumata Léonie Francois ${ }^{1}$, Karamoko Sacko', \\ Djeneba Konaté1, Guediouma Dembele1, Hacimi Poma1, Adama Bah1, Djibril Kassogue1, \\ Oumar Keita², Ibrahim Ahamadou ${ }^{1}$
}

\author{
${ }^{1}$ Department of Pediatrics at CHU Gabriel Touré, Bamako, Mali \\ ${ }^{2}$ Pediatric Surgery Department of the Gabriel Touré CHU, Bamako, Mali \\ ${ }^{3}$ Pathological Anatomy and Cytology Department of the "Point G" CHU, Bamako, Mali \\ Email: ^doumbiav@gmail.com
}

How to cite this paper: Doumbia, A.K., Dembele, A., Togo, P., Coulibaly, O., Dackono, A., Cissé, M.E., Traoré, F., Diall, H., Togo, B., Diakité, A.A., Coulibaly, Y., Traore, C.B., Sidibe, L.N., Maiga, B., Francois, D.F.L., Sacko, K., Konaté, D., Dembele, G., Poma, H., Bah, A., Kassogue, D., Keita, O. and Ahamadou, I. (2021) Clinico-Pathological Profile of Malignant Abdominal Tumors in Children: Experience of the Pediatric Oncology Unit in Bamako. Open Journal of Pediatrics, 11, 608-617. https://doi.org/10.4236/ojped.2021.114056

Received: September 18, 2021 Accepted: November 14, 2021 Published: November 17, 2021

Copyright $\odot 2021$ by author(s) and Scientific Research Publishing Inc. This work is licensed under the Creative Commons Attribution International License (CC BY 4.0).

http://creativecommons.org/licenses/by/4.0/ (c) (i) Open Access

\begin{abstract}
Introduction: the objective was to describe the epidemiological and histological aspects of malignant abdominal tumors in children. Methodology: This was a descriptive, cross-sectional study conducted from January 1, 2017 to December 31, 2018. We included all patients aged 0 to 15 years with histologically confirmed abdominal malignancies. Results: We collected 46 files of malignant tumors of the abdomen (35\% of pediatric cancers). The majority of patients were under 5 years old $(65 \%)$. The sex ratio was 1.7. They were generally from disadvantaged socio-economic backgrounds (67\%). The average consultation time was 50 days. The main reasons for consultation were abdominal mass (48\%), pain (17\%) or distension (9\%). The mass was large, hard (89\%), immobile (71\%) and painful (46\%). Malnutrition was found in $80 \%$ of patients. The mass was retro-peritoneal in $63 \%$ of cases and renal in $54 \%$. It was solid in $94 \%$ of cases and heterogeneous in $76 \%$ of cases. The assay for tumor markers was not performed. Anemia was present in all patients. Fine needle aspiration was performed in $43 \%$, biopsy in $37 \%$ and myelogram in $15 \%$ of cases. spinal cord involvement was observed in $28 \%$ of Burkitt's cases. The main cancers diagnosed were nephroblastoma (52\%), Burkitt's lymphoma (26\%) and neuroblastoma (13\%). Stage 1 and stage 2 were frequent in $20 \%$ and $22 \%$ of cases, respectively; $36 \%$ of cases were not staged. The average duration of chemotherapy was 11 weeks. Total resection was
\end{abstract}


performed in $30 \%$ of cases. The outcome of the patients was marked by total remission in 65\%. Conclusion: Abdominal malignancies are very common in children. The diagnosis of certainty is late in our context.

\section{Keywords}

Cancer, Abdomen, Child, Sub-Saharan Africa

\section{Introduction}

Abdominal tumor requires rapid and precise diagnosis for effective management [1]. Malignant abdominal tumors in children represent the set of expansive malignant processes that develop in the abdominal cavity [2]. They are often discovered incidentally by a parent, during a physical examination or detected on abdominal imaging [3]. They usually present in the form of an abdominal mass or an increase in abdominal volume, or by non-specific signs: digestive and voiding disorders (by compression), arterial hypertension, hematoma, general signs (fever, weight loss), rarely a complication (acute intussusception) [2].

Patient age, gender and tumor topography are fundamental to diagnostic guidance. Between 1 and 6 years of age, the majority of the masses are of a malignant nature, mainly neuroblastoma and nephroblastoma [4]. The discovery of an abdominal mass in the child leads to the performance of additional radiological, biological and pathological examinations. These examinations are best carried out in a specialized environment with the aim of rapidly leading to the aetiological diagnosis and the initiation of effective treatment.

Imaging has greatly contributed to improving the diagnosis of abdominopelvic cancers and monitoring the effectiveness of treatment. Conventional ultrasound is often the first-line examination, but overall has a limited role in the diagnosis and classification of abdominopelvic cancer [3] [4]. Computed tomography is currently the main diagnostic tool used in oncological radiology. MRI is generally used as a second-line due to its cost and relatively limited availability [4]. Imaging can locate the tumor, study its relationships, determine if possible the nature and highlight vascular lesions. The choice of technique is determined according to the organ studied, the suspected pathology, the clinical condition of the patient and the experience of the radiologist and endoscopist [4]. According to the literature, about two-thirds of malignant abdominal tumors are retro-peritoneal. The majority of these retroperitoneal tumors are intra-renal [5]. Biology, in particular the dosage of markers (tumor markers), retains an important place in the diagnostic process. We can look for an increase in alpha-fetoprotein in dysembryoma, an increase in gonadotropic chorionic hormone (beta-HCG) in chorio-carcinomatous tumors.

Surgery helps both diagnosis and treatment. The definitive diagnosis depends on the pathologist. A multidisciplinary consultation (oncologist, radiologist, surge- 
on, pathologist) makes it possible to plan the treatment, the first step of which is often, but not necessarily, chemotherapy.

In Mali, the exact incidence of pediatric cancers and malignant abdominal tumors remains unknown. The aim of this study was to describe the demographic, clinical, pathological and evolutionary aspects of malignant abdominal tumors in children in the pediatric oncology unit in Bamako.

\section{Methodology}

This was a cross-sectional study, which took place at the pediatric oncology unit (UOP) and the recovery and intensive nutritional education unit (URENI) of the CHU Gabriel Touré in Bamako. UOP was the only care center for children with cancer in Mali. He understands:

- Ten (10) individual hospital rooms;

- One (1) room for the preparation of chemotherapy;

- One (1) infirmary;

- Three (3) offices.

- An outpatient room commonly called "day hospital also serving as a gesture room (cyto-puncture, myelogram, lumbar puncture).

The staff of the UOP consists of:

- Four (4) pediatric oncologists including a full professor;

- One (1) general practitioner;

- Five (5) nurses trained in cancer care.

The unit's activities are mainly the diagnosis, treatment and follow-up of children with cancer. The Day Hospital receives patients at the diagnostic stage and those who come for follow-up visits to the unit. The treatments are administered by the day hospital or in hospital according to the protocols.

URENI staff is made up of:

- A supervising pediatrician;

- A senior health technician;

- A health technician;

- Two caregivers.

The study took place over a 2-year period from January 1, 2017 to December 31,2018 . We recruited all cases of malignant abdominal tumors followed by the OPU and having a well-completed and well-maintained medical record. The patients included in this study were children aged 0 to 15 years who presented an abdominal tumor explored by ultrasound and/or computed tomography (CT) and confirmed by the pathologist.

Patients with an uncertain diagnosis or an unusable or ill-informed medical record were not selected. Those who had not benefited from paraclinical exploration and whose etiology had not been clearly demonstrated were excluded from the study.

The data had been collected on individual survey forms from medical records and department records. 
The management and monitoring of patients' patients were multidisciplinary (oncologists, surgeons, pathologists, anesthesiologists). The duration of the follow-up depended on the etiological diagnosis and the residence of the patients. The variables studied were socio-demographic, clinical, radiological (ultrasound and scanner), biological, diagnostic, evolutionary and therapeutic management data. Data entry and analysis were performed with Microsoft Word 2019 software and SPSS.20 software.

This study was carried out under the authorization of the management of CHU Gabriel Toure and with the supervision and collaboration of physicians from the general pediatrics department. The results of this work will help lay the foundations for early diagnosis and adequate management of malignant abdominal tumors in Mali.

\section{Results}

This study included 46 records of patients with a malignant abdominal tumor. The sex ratio was 1.7. Children under 5 made up $65 \%$ of the workforce. In this study, five patients (or 10\%) were less than one year old, $54 \%$ of patients were between one and six years old, 20\% were between six and 10 years old and 15\% were between 10 and 15 years old. years. The mean age was 5.2 years with extremes of 4 months and 14 years (Table 1). The patients were educated in 20\% of cases. The patients resided outside Bamako in 57\% of cases. Patients were referred in $87 \%$ of cases for abdominal mass. They were referred for suspected

Table 1. Distribution of the number of patients by age.

\begin{tabular}{|c|c|c|c|c|c|c|}
\hline \multicolumn{2}{|c|}{ Patient's age } & \multicolumn{2}{|c|}{ Numbers $(n=46)$} & \multicolumn{3}{|c|}{$\%$} \\
\hline \multirow{3}{*}{1 to 12 months } & 4 months & 1 & & 2 & \multirow{3}{*}{\multicolumn{2}{|c|}{10}} \\
\hline & 8 months & 1 & 5 & 2 & & \\
\hline & 9 months & 2 & & 4 & & \\
\hline \multirow{5}{*}{1 to 5 years } & 1 year & 2 & & 4 & \multirow{5}{*}{\multicolumn{2}{|c|}{55}} \\
\hline & 2 years & 3 & & 7 & & \\
\hline & 3 years & 9 & 25 & 20 & & \\
\hline & Four years & 8 & & 17 & & \\
\hline & 5 years & 4 & & 9 & & \\
\hline \multirow{4}{*}{6 to 10 years } & 6 years & 2 & & 4 & \multirow{4}{*}{20} & \\
\hline & 7 years & 2 & & 4 & & \\
\hline & 8 years & 1 & & 2 & & 35 \\
\hline & 9 years & 4 & & 9 & & \\
\hline \multirow{3}{*}{$\begin{array}{c}11 \text { to } 15 \text { years } \\
\text { old }\end{array}$} & 12 years & 4 & & 9 & \multirow{3}{*}{15} & \\
\hline & 13 years & 1 & & 2 & & \\
\hline & 14 years old & 2 & & 4 & & \\
\hline
\end{tabular}


cancer in $35 \%$ of cases. The parents' socioeconomic level was unfavorable in $67 \%$ of cases. No notion of familial cancer was found. The tumor was discovered by the mother in $33 \%$ of cases. The patients consulted for mass in $48 \%$ of cases or for abdominal pain in $17 \%$ of cases (Table 2). They had been referred for suspected cancer in $35 \%$ of cases.

The average consultation time was 12 weeks with extremes of 2 and 52 weeks. The mean time to diagnosis was 8 days with extremes of 1 and 45 days. The tumor was most often hard (89\%), immobile (72\%) and painful (46\%). The tumor was retro-peritoneal in $65 \%$ of cases (Table 3 ). The mass was localized in the flanks (left or right) in 35\% of cases and diffuse in 19\% of cases.

The clinical examination also observed weight loss (80\%), lymphadenopathy (22\%) and fever (17\%) (Table 4).

The tumor was solid in $93 \%$ and heterogeneous in $76 \%$ of cases. The tumor was metastatic in $24 \%$ of cases. Metastases were localized to the lungs in $12 \%$. The hemoglobin level was less than $8 \mathrm{~g} / \mathrm{dl}$ in $35 \%$ of cases. Platelet counts were lowered in $11 \%$ of cases and abnormally high in $35 \%$ of cases. The leukocyte count was elevated in $11 \%$ of cases. The cytopuncture was performed in $43 \%$; a biopsy was performed in $37 \%$ of cases and a myelogram was performed in $15 \%$ of cases. Bone marrow invasion was observed in 3 out of 7 cases. Table 5 shows

Table 2. Breakdown of the number of patients according to the reason for consultation or referral.

\begin{tabular}{ccc}
\hline Reason for consultation & Numbers $(\mathbf{n}=46)$ & $\%$ \\
\hline Abdominal mass & 22 & 48 \\
Abdominal pain & 8 & 17 \\
Abdominal distension & 4 & 9 \\
Suspicion of lymphoma & 3 & 7 \\
Suspicion of nephroblastoma & 3 & 7 \\
Haematuria & 2 & 4 \\
AEG & 1 & 2 \\
Ascites & 1 & 2 \\
Subclavicular mass & 1 & 2 \\
Polyadenopathies & 1 & 2
\end{tabular}

Table 3. Distribution of the number of patients according to the location of the tumor.

\begin{tabular}{|c|c|c|c|}
\hline \multicolumn{2}{|c|}{ Location } & \multirow{2}{*}{$\begin{array}{c}\text { Numbers }(n=46) \\
25\end{array}$} & \multirow{3}{*}{$\begin{array}{l}\% \\
65\end{array}$} \\
\hline \multirow{2}{*}{ Retro peritoneal } & Renal & & \\
\hline & Extrarenal & 5 & \\
\hline \multirow{2}{*}{ Intraperitoneal } & Hepatic & 1 & \multirow{2}{*}{33} \\
\hline & Extrahepatic & 13 & \\
\hline \multicolumn{2}{|c|}{ Abdominopelvic } & 2 & 4 \\
\hline
\end{tabular}


Table 4. Distribution of the number of patients according to the associated signs.

\begin{tabular}{ccc}
\hline Associated signs & Numbers & $\%$ \\
\hline Weight loss & 37 & 80 \\
Lumbar contact & 24 & 63 \\
Lymphadenopathy & 10 & 22 \\
Fever above $38^{\circ} \mathrm{C}$ & 8 & 17 \\
Respiratory distress & 5 & 11 \\
Ascites & 5 & 11 \\
Splenomegaly & 5 & 11 \\
Hepatomegaly & 5 & 11 \\
Skin lesions & 2 & 4 \\
\hline
\end{tabular}

Table 5. Distribution of the number of patients according to the etiological diagnosis.

\begin{tabular}{llcc}
\hline & Variables & Numbers $(\mathbf{n}=46)$ & $\%$ \\
\hline Types of cancers & Nephroblastoma & 24 & 52 \\
& Burkitt's lymphoma & 12 & 26 \\
& Hodgkin's disease & 1 & 2 \\
& Large B cell lymphoma & 1 & 2 \\
& Neuroblastoma & 6 & 13 \\
& Hepatoblastoma & 1 & 2 \\
& TGM & 1 & 2 \\
\hline Stage of tumor & Not classified & 16 & 35 \\
& Stage 1 & 9 & 20 \\
& Stage 2 & 10 & 22 \\
& Stage 3 & 4 & 9 \\
Stage 4 & 6 & 2 \\
\hline
\end{tabular}

the different types of cancer observed during this study. Nephroblastoma was the most frequently diagnosed cancer (52\%).

The cancer was stage 1 in $20 \%$ of cases and stage 2 in $22 \%$ of cases. It was not classified $36 \%$ of the time. The patients had received chemotherapy in $98 \%$ of cases. The patients were treated according to the protocols proposed by the Franco-African pediatric oncology group (Table 6).

The average duration of chemotherapy was 11 weeks with extremes of 1 week and 42 weeks. Toxicities were observed in $80 \%$ of cases. Haematological toxicity was observed in $54 \%$ of cases and digestive toxicity in $56 \%$ of patients. Total resection was performed in $30 \%$ of patients. Remission was observed in $65 \%$ of patients and $56 \%$ of patients survived the disease (Table 7 ). The majority 
Table 6. Breakdown of the number of patients according to the protocol used.

\begin{tabular}{ccc}
\hline Protocol used & Numbers $(\mathbf{n}=\mathbf{4 6})$ & $\%$ \\
\hline GFA Nephro 2005 & 18 & 39 \\
GFAOP & 22 & 48 \\
VP16/Carbo & 2 & 4 \\
VP16/Carbo/CO & 2 & 4 \\
Modified LMB & 1 & 2 \\
No protocol & 1 & 2 \\
\hline
\end{tabular}

Table 7. Distribution of the number of patients according to the evolution.

\begin{tabular}{ccc}
\hline Evolution of the tumor & Numbers & $\%$ \\
\hline Remission & 30 & 65 \\
Relapse & 1 & 2 \\
Lost view & 13 & 28 \\
Living & 26 & 56 \\
Deceased & 9 & 20 \\
\hline
\end{tabular}

of reported deaths $(76 \%)$ occurred in a decompensated anemia picture.

\section{Comments and Discussion}

There are few epidemiological studies of malignant abdominal tumors in children. During the study period, childhood MAPs accounted for $16 \%$ of pediatric cancers. The incidence of cancer is difficult to assess in Mali because of the lack of hospital cancer registries. The majority of MAT occurred in children under 5 years of age with a predominance of men. This male predominance of pediatric tumors had been reported by many African authors without any precise explanation for this finding [6].

There was great heterogeneity in the socio-demographic distribution of our patients. The majority of patients came from rural areas (57\%), where diagnostic facilities are even more limited. The average consultation time was relatively long (12 weeks). While a history, careful physical examination, basic laboratory and correct imaging studies can provide sufficient information to determine the diagnosis or refer to the appropriate specialists [7]. In France, where exercise conditions are better, rapidly growing embryonic tumors are diagnosed earlier, with a median duration of less than one month [8]. The long diagnostic delay could be explained by household poverty, customary practices and beliefs and the shortage or lack of qualified personnel [9].

In this study, the main way of revealing MAT was abdominal mass. The clinical manifestations were variable, depending mainly on the location, the size of the tumor and the existence of metastases. The majority of malignant abdominal tumors were retroperitoneally represented by nephroblastoma and neuroblasto- 
ma. In this study, the commonly diagnosed MAT were nephroblastoma (52\%), lymphoma (30\%), and neuroblastoma (13\%). Our results were very close to those reported in the literature [10] [11] [12].

Nephroblastoma is an almost specific tumor in children, most commonly occurring between 1 and 5 years of age with a peak incidence around the age of 3.5 years [13]. It is an embryonic tumor with very heterogeneous histology characterized by epithelial, stromal and blastematous components [14].

In this study, non-Hodgkin lymphoma was the second leading cause of the malignant abdominal tumor. Burkitt's lymphoma is thought to be prevalent in sub-Saharan Africa because of the high frequency of Epstein-Barr virus (EBV) infection and Plasmodium falciparum malaria [9] [15] [16] [17].

Neuroblastoma is a tumor that develops from the sympathetic nervous system. It is the most common solid extracranial tumor in childhood [18]. In this study, it was the third leading cause of abdominal cancer in this study. According to the literature, it is the second most common solid tumor in children, after central nervous system tumors [18]. Stage, histologic type and age are the most important prognostic markers [19].

In this study, $98 \%$ of patients had received chemotherapy adapted according to the GFAOP protocol. Surgical excision was performed in $30 \%$ of cases; these were mainly cases of nephroblastoma. Surgical abstention was the rule in cases of lymphoma and whenever the tumor was huge with multifocal adhesions and metastases (neuroblastoma).

The evolution of the patients, with a mean follow-up of 12 months, was marked by complete remission in $65 \%$ of cases (30 patients), relapse in $2 \%$ of cases ( 1 patient), death in $19 \%$ of cases (9 patients). Discontinuation of treatment was observed in $28 \%$ of patients. Several causes could explain the unfavorable prognosis of abdominal cancer, including a lack of specialists, difficulties in the supply of anticancer drugs, lack of supportive care, and a lack of financial means [9]. These factors, associated with endemic malnutrition and recurrent infectious pathologies, constitute obstacles to obtaining cure and survival rates comparable to those in developed countries [9] [20].

\section{Conclusion}

This study allowed us to better understand the epidemiological, clinical and evolutionary characteristics of malignant abdominal tumors at the UOP of Bamako. The majority of patients were under 5 years old; the main etiologies of MAT were nephroblastoma (52\%), lymphomas (30\%) and neuroblastoma (13\%). The diagnosis and management of abdominal cancers were most often late. Efforts must be made to strengthen the education of populations on pediatric cancers.

\section{Conflicts of Interest}

The authors declare no conflicts of interest regarding the publication of this paper. 


\section{References}

[1] Amdes, S., Barbuto, T.M., Freitas, F.A., et al. (2017) An Unusual Abdominal Wall Mass in a Child. Revista do Instituto de Medicina Tropical de São Paulo, 59, e16. https://doi.org/10.1590/s1678-9946201759016

[2] Khan, P.S., Akhter, Z., Majeed, S., et al. (2015) Clinicopathological Profile of Childhood Primary Abdominal Tumours in Kashmir. Indian Journal of Surgery, 77, 361-364. https://doi.org/10.1007/s12262-013-0843-2

[3] Potisek, N.M. and Antoon, J.W. (2017) Abdominal Masses. Pediatrics in Review Février, 38, 101-103. https://doi.org/10.1542/pir.2016-0087

[4] Eberhardt, S.C., Johnson, J.A. and Parsons, R.B. (2013) Oncology Imaging in the Abdomen and Pelvis: Where Cancer Hides. Abdominal Imaging, 38, 647-671. https://doi.org/10.1007/s00261-012-9941-z

[5] Sarnacki, S., Brisse, H., Schleiermacher, G. and Doz, F. (2009) Conduite à tenir devant la découverte d'une tumeur abdominale de l'enfant. Médecine Thérapeutiquel Pédiatrie, 12, 29-38.

[6] Zareifar, S., Haghpanah, S., Farahmandfar, M.R., et al. (2016) Clinicopathologic Characteristics of Malignant Abdominal Tumors in Children: 10 Years Experiences. Iranian Journal of Pediatric Hematology and Oncology, 6, 142-148.

[7] Weiser, D.A., Kaste, S.C., Siegel, M.J. and Adamson, P.C. (2013) Imaging in Childhood Cancer: A Society for Pediatric Radiology and Children's Oncology Group Joint Task Force Report. Pediatric Blood \& Cancer, 60, 1253-1260. https://doi.org/10.1002/pbc.24533

[8] Tatencloux, S., Mosseri, V., Papillard-Maréchal, S., Mesples, B., et al. (2017) Parcours pré-diagnostique des enfants et adolescents atteints de tumeurs solides. Bulletin $\mathrm{Du}$ Cancer, 104, 128-138. https://doi.org/10.1016/j.bulcan.2016.11.002

[9] Togo, B., Traoré, F., Togo, A.P., Togo, P., et al. (2014) Épidémiologie et pronostic des cancers pédiatriques au CHU Gabriel-Touré de Bamako (Mali). Médecine et Santé Tropicales, 24, 68-72. https://doi.org/10.1684/mst.2014.0291

[10] Golden, C.B. and Feusner, J.H. (2002) Malignant Abdominal Masses in Children: Quick Guide to Evaluation and Diagnosis. Pediatric Clinics of North America, 49, 1369-1392. https://doi.org/10.1016/S0031-3955(02)00098-6

[11] Pérel, Y. and Plantaz, D. (2009) Cancer de l'enfant, springer science et business media cancérologie de l'enfant. Mai. Elsevier, Amsterdam.

[12] Rai, A.T. and Moazam, F. (1996) Malignant Abdominal Tumors in Children. Journal of Pakistan Medical Association, 46, 168-171.

[13] Schleiermacher, G. and Brisse, H. (2006) Le néphroblastome. Oncology (Paris), 8, 555-562. https://doi.org/10.1007/s10269-006-0450-y

[14] Perlman, E. and Boccon-Gibod, L. (2004) Tumeurs du rein de l'enfant. In: Annales de Pathologie, Elsevier Masson, Amsterdam, 516-535.

https://doi.org/10.1016/S0242-6498(04)94016-3

[15] Patte, C., Brugières, L. and Terrier-Lacombe, M.J. (2008) Lymphomes malins non-Hodgkinien de l'enfant. In: Kalifa, C., Oberlin, O., Pein, F., et al., Eds., Cancer de P enfant, Flammarion Médecine-Science, Paris, 157-168.

[16] Ngoma, T., Adde, M., Durosinmi, M., et al. (2012) Treatment of Burkitt Lymphoma in Equatorial Africa Using a Simple Three-Drug Combination Followed by a Salvage Regimen for Patients with Persistent or Recurrent Disease. British Journal of Haematology, 158, 749-762. https://doi.org/10.1111/j.1365-2141.2012.09236.x

[17] Mhamed, H. (2012) Cancer in Children: Practical Aspects. Morocco Printing, 39-50. 
[18] Tolbert, V.P. and Matthay, K.K. (2018) Neuroblastoma: Clinical and Biological Approach to Risk Stratification and Treatment. Cell and Tissue Research, 372, 195-209. https://doi.org/10.1007/s00441-018-2821-2

[19] Normand, C., Michon, J., Janoueix-Lerosey, I., Delattre, O. and Schleiermacher, G. (2011) Les altérations génétiques dans le neuroblastome et leur apport pour la prise en charge thérapeutique. Bulletin du Cancer, 98, 477-488.

https://doi.org/10.1684/bdc.2011.1364

[20] Ka, A.S., Imbert, P. and Moreira, C. (2003) Epidemiologie et pronostic des affections malignes de l'enfant à Dakar, Sénégal. Medecine Tropicale, 63, 521-526. 